\title{
1968: Caminhando e cantando e protestando e apanhando ${ }^{1}$
}

\author{
Luiz Roberto Lopez ${ }^{2}$
}

Résumé: Comme son titre l'indique, cet essai étudie 1968 en établissant des rapports entre la vie politique et la vie culturelle. Il est organisé en deux parties. La première met en évidence les sentiments de révolte et de protestation qui animent toute cette époque et mobilisent les peuples (en particulier la jeunesse, surtout les lycéens et les étudiants, mais pas uniquement); elle signale aussi que, d'une part, la volonté de contestation n'était pas seulement politique et sociale, mas concernait également les comportements et la vie sexuelle et que, d'autre part, la gauche qui en donnait une expression politique était diverse et hétérogène. La deuxième partie se penche sur le Brésil, montrant que la culture y fut une arme de résistance et que le terrain culturel y fut l'enjeu d'un combat opposant une culture progressiste à une culture aliénée.

Palavras-chave: 1968; política; comportamentos; cultura; Brasil.

Em 1967, o Brasil já vivia a fase militar. Castelo Branco passou o poder a um colega de farda - Costa e Silva. Representava a chamada linha dura, que defendia a permanência dos donos da caserna indefinidamente no poder. É verdade que, no discurso de posse, Costa e Silva acenou com propostas liberalizantes. Se aquilo era intenção de verdade ou mera retórica de começo de Governo, jamais saberemos, pois intrometeu-se, no seu mandato,o ano de $1968 \ldots$

\section{Os anos de protestos}

$\mathrm{O}$ chamado ano que não acabou foi assinalado por vários protestos em vários lugares do mundo. $\mathrm{O}$ impulso ideológico foi diversificado e heterogêneo, embora orientado na direção da esquerda. A liderança foi estudantil. Ideais anarquistas, socialistas, terceiro-mundistas, libertários em geral, os mais diversos e controversos se fundiram e confundiram. Tinham em comum a vontade e a vocação da contestação. Os jovens se constituíram na vanguarda e se opunham às restrições, convenções e proibições da sociedade estabelecida. Queriam a revolução social e comportamental e percebiam que ambas se interpenetravam. Os lemas é proibido proibir e sejamos realistas, peçamos o impossível davam o tom dos protestos. Tanto defendiam a liberdade sexual como a liberdade política. Tanto combatiam a proibição do LSD como a exploração imperialista. Igualmente exigiam a paz mundial e o fim das ditaduras latino-americanas. Em princípio, eram contra qualquer forma de autoritarismo e faziam da desconfiança dos mais velhos o ponto de partida. De mesmo modo, eram avessos a todos os partidos, os quais eram entendidos como viciados, esclerosados e incapazes de representar algo efetivamente novo.

Maio virou referência de todo um ano, porque, em Paris, naquele mês, a temperatura política da agitação chegou ao nível mais elevado. Parecia até revolução. Sintomaticamente, os ídolos da época não eram Lênin ou Marx, mas Che Guevara, Ho Chi Minh, Mao Tse-Tung, os líderes revolucionários do Terceiro Mundo. E claro, Timothy Leary, Janis Joplin, Jimi Hendrix e Bob Dylan - megaestrelas da sociedade urbana de consumo. O lado agressivo do rock e da droga se tornavam símbolos de liberdade.

Com suas contradições de classe média, os jovens protestaram. Tinham vagas aspirações, não tinham exatamente um programa. Sabiam o que não queriam, e isso parecia suficiente - e foi o ponto que conferiu legitimidade a toda a luta de uma geração. Entretanto, era, no fundo, também uma luta

\footnotetext{
1 Primeira publicação em: PONGE, Robert (Org.). 1968, o ano das muitas primaveras. Porto Alegre: Unidade Editorial da Secretaria Municipal de Cultura da Prefeitura Municipal, 1998. p. 159-164.

${ }^{2}$ Luiz Roberto Lopez (1948-2004): graduado em História e especialista em História da América pela UFRGS; foi historiógrafo da Secretaria de Cultura do Estado do Rio Grande do Sul, diretor da discoteca pública Natho Hehn e do Memorial do Rio Grande do Sul (ambos ligados à Secretaria de Cultura do Estado do Rio Grande do Sul), professor de história do curso pré-vestibular Unificado e docente do Departamento de História da UFRGS, onde lecionou História da Cultura. Autor de nove livros (publicados pela Editora Mercado Aberto ou pela Editora da UFRGS) e de numerosos artigos.
} 
estruturalmente frágil e acabou esgotada. Como bem detectou Marcuse - um dos gurus do momento - não só foram dizimados pela repressão, como também pelo fato de que tudo aquilo foi análogo à agitação das ondas do mar: só atingem a superfície, pois, no fundo, as águas correm calmas. Enfim, os estudantes realizaram passeatas e manifestações, mas não lograram mobilizar o grosso da sociedade, as tais águas calmas da metáfora de Marcuse. Ao cabo, as agitações de 1968 deixaram de herança, a guerrilha urbana, de um lado, e, de outro, os hippies e sua felicidade marginal.

A uma primeira vista, talvez pareça pequena a herança para um ano tão agitado e repleto de esperanças, a partir das transgressões. No entanto, tanto a guerrilha como os hippies refletiram anseios permanentes, subjacentes naquele contexto. A guerrilha prolongou, de modo dramático, um protesto em que o lado político se mesclara ao lado cultural e comportamental, conferindo-lhe um aspecto lúdico. Com os enfrentamentos urbanos e a formação de grupos de guerrilheiros, que operaram em vários países, ao longo dos anos setenta, jovens de classe média deram vazão a um ímpeto transformador que se esgotara, enquanto modalidade de ação, em 1968 - nesse caso, ficou de fora o lado lúdico.

Ao contrário, a figura do hippie, outro prolongamento das fermentações de 1968, foi justamente a continuação do lado lúdico que a seriedade e situação-limite própria da guerrilha não permitiram incorporar. O hippie foi uma filosofia de vida que, tal como a guerrilha, atuou nas franjas da sociedade, mas questionando através do exemplo e visando, ostensivamente,agir à margem da sociedade de consumo, sem enfrentamentos violentos com o sistema.

Ambos os fenômenos terminaram perdendo a força e não lograram destruir, a bem da verdade, o establishment, mas trouxeram à luz diversas contradições evidentes no cotidiano no universo capitalista, revelando seu conservadorismo estrutural e a heteróclita pluralidade social que fazia questão de se manifestar. Sob tal ângulo, 1968 sinalizou uma ruptura e uma - controvertida que seja - etapa da modernidade ocidental.

\section{E o Brasil?}

No caso brasileiro, os estudantes há tempos já vinham dando o rumo dos protestos, e 1968 os incentivou, mas não foi uma causa. A ditadura militar estava fechando os espaços de rua, e os estudantes, sobretudo pela sua atuação política militante antes do golpe, eram especialmente visados. Naquele período, é importante assinalar que ainda não começara o milagre entorpecedor - o regime impusera uma política recessiva que, em última análise, ameaçava exatamente o futuro de uma juventude a caminho do mercado de trabalho.

Multiplicaram-se, em 1967, os protestos contra a política governamental, e a questão era tratada como problema policial. Foi a partir dessas realidades que a cultura se engajou no arsenal da oposição ativa dos jovens. O engajamento da cultura no processo de renovação da sociedade brasileira não era novo - nos inícios dos anos sessenta, já fazia parte da estratégia da UNE - União Nacional de Estudantes, através dos CPCs - Centro Populares de Cultura. Após o golpe, com a repressão restringindo o uso da rua, a sua força refluiu para o palco - sobretudo através de shows da MPB e dos famosos festivais. Já em 1967, o Tropicalismo - Gil, Caetano - iniciara sua transgressão colorida, e Chico, Edu Lobo e outros tinham começado, em grau crescente, a fazer da MPB urbana o canal para exprimir a contestação.

Entende-se que a manifestação cultural que melhor se adequou aos protestos daquele período, tenha sido a MPB - ela provocava impacto direto e atingia o público urbano, que constituía a vanguarda da luta e da contestação. Como elemento catalizador, funcionou mais a contento que qualquer outra arte. Por outro lado, há que fazer distinção entre o protesto do tipo Chico e o protesto tipo Caetano. Chico representava a música propriamente engajada, politizada ostensivamente - direta herdeira da linha do CPC - ao passo que Caetano encarnava uma transgressão mais comportamental, sem vínculo aberto e direto com a questão social. Em duas linhas poéticas diferentes, o que não impediu que ambas fossem igualmente apreciadas pelo mesmo público.

Quando se escuta o sarcasmo lírico/poético do Chico Buarque daqueles anos, a conscientização política entra como um punhal, e a poesia fornece o indispensável contorno a uma mensagem direta. De maneira notável, Chico inventou uma música para reforçar a letra, simples e impactante em seu melodismo. Ás vezes, lembrando as pinturas de Guignard, Pancetti, Volpi ou Marcier, assim como certas Bachianas de Villa Lobos, escrevia músicas com sabor interiorano, evocando rincões perdidos do Brasil, como em A banda ou em Valsinha, mas o que o tornou uma referência de protesto contra a ditadura que ganhava terreno, foram, sem dúvida, as composições fortes falando da repressão, da liberdade ou da injustiça social. Muitas já se tornaram clássicas, dentre as várias daquele período. Quem não conhece Deus lhe pague ou Apesar de você ? A primeira fala, cortante como uma navalha, do desamparo de um operário da construção civil que despenca de um andaime, flutua no ar "como se fosse um príncipe" e se esborracha na rua "atrapalhando o sábado". Toda a música é um inesquecível jogo de palavras a

Organon, Porto Alegre, n 47, julho-dezembro, 2009, p.79 - 84 
enriquecer idéias. Quanto à segunda música, embora se possa ver uma alusão ao general Médici - "apesar de você, amanhã há de ser outro dia" - deve-se registrar que ela tem, certamente uma leitura mais ampla, em nível simbólico, aludindo ao retorno da luz, que inevitavelmente se segue às sombras, trazendo uma mensagem de esperança.

Diferentemente de Chico, o protesto encarnado por Caetano tinha um caráter menos direcionado. Originado do grupo "Novos Baianos", Caetano, na linha do "caldeirão nacional" da Antropofagia dos idos de 1926-1928, propunha geléia-geral. Seu guru imediato era a arte não-convencional e antiacadêmica de Hélio Oiticica, defensor das delícias da transgressão com seus parangolés e seus labirintos multicores. Caetano pretendia um Brasil que valorizasse sua multiplicidade e o fascínio de seus contrastes e contradições. Seu clássico Alegria, alegria é uma declaração de princípios - na qual o cantor não tem "lenço ou documento", isto é, não tem uma identidade bem-comportadda e, dando de ombros, se limita a festejar um Brasil de muitas cores e identidades, no qual convivem o moderno e o arcaico e o Sol tudo ilumina, inclusive as "cardinales bonitas".

A posição de Caetano, que chegou a ter dissabores com os mais exaltados da ala politizada, foi a de registrar o nacional-popular pelo lado da variedade, aceitando que o Brasil é tudo, evitando impregnar sua música de um conteúdo político assumido, no sentido de criticar a ditadura, exigir a democracia, combater o imperialismo ou a injustiça social. Caetano se pôs contra as convenções para enaltecer o direito de ser diferente e de ter uma liberdade lúdica e não tirou da transgressão senão o seu lado luminoso. Não transformou o anticonvencionalismo em uma atitude com consequências políticas.

Afora a MPB, registra-se ainda que, no prolongamento do Cinema Novo e de seu realismo crítico, Glauber Rocha, em 1968, deu à luz Terra em transe, um libelo contra o subdesenvolvimento e a miséria do meio agrário. Glauber, com sua linguagem barroca, fez na tela aquilo que os compositores e cantores faziam no palco da MPB. No começo daquele ano, a peça Roda viva, de Chico, provocou viva controvérsia - era um questionamento forte e direto da manipulação da vida humana pelos interesses do lucro da sociedade de massas, e a mensagem se dirigia exatamente para a sociedade de massas, numa linguagem que ela entendia. Pouco depois, num festival no Maracanãzinho, Geraldo Vandré criou a mais importante música de toda esta fase de engajamentos: Caminhando ou Para não dizer que não falei de flores. Não levou o prêmio, mas ganhou a multidão: sem efeitos especiais, apenas ele e seu violão. A obra-prima para a mobilização e o protesto, hoje, um símbolo de uma época.

Ainda no palco, merece referência como arte de protesto naquele período, o teatro, o qual prolongou uma linha que vinha do Teatro de Arena e do Oficina. Dias Gomes, que já tinha uma trajetória nesse sentido, escreveu Berço do Herói. E Plínio Marcos trouxe suas peças corrosivas sobre o universo da marginalidade urbana, avultando, entre outras, Navalha na carne e Quando as máquinas param, esta última, um libelo contra a desumanidade do desemprego, centrado em dois personagens patéticos, compondo um drama de elevada temperatura social. Teatro, música e cinema se davam as mãos para fazer da cultura um eficiente instrumento de luta política.

O contraponto dessa arte de conscientização, combustível para protestos ora festivos, ora explosivos, embora o governo militar ainda não tivesse sua oferta cultural para fabricar uma ideologia a serviço das elites, também existiu: ao cinema de Glauber, Walter Hugo Khoury opôs os seus filmes intimistas, eróticos e entendiados que, à engajada de Chico e Vandré, Roberto Carlos e a turma da "brasa mora" opunham suas cançõezinhas desfibradas, aparentemente "modernas", manifestamente sentimentalóides, destinadas ao mesmo público dos engajados e oferecendo suspiros e alienação em lugar da conscientização e da luta. Em resumo, no confronto entre uma cultura progressiva e outra alienada, percebe-se como se travou, no âmbito artístico, naquele ano tumultuado, a luta de classes.

No final de 1968, a decretação do AI-5 encerrou uma fase combativa e impôs o silêncio à sociedade civil. Em 1969, começaria o período Médici, os chamados anos de chumbo. A repressão passaria a incluir a área cultural em bloco. Os artistas foram compelidos ao exílio ou a uma virtual clandestinidade social, para não falar nos que foram presos e torturados. Logo, junto com seu milagre, a ditadura começaria também a ofertar seu projeto cultural, integrando a produção artística ao novo ethos capitalista e forjando toda uma ideologia sobre bens culturais criados a partir da ótica do governo de caserna. Vandré foi silenciado, enquanto Roberto Carlos continuou cantando.

É verdade que aqueles jovens de 1968 tinham muita confusão e idéias desencontradas e que combateram em meio à desorganização, enfrentando forças poderosas, numa luta desigual, entretanto, eles tinham a legitimidade da dignidade e do humanismo e isso permaneceria, ao som baixinho da música de Vandré, como uma luz no fundo dos escombros. 